\title{
DES HOMMES NOIRS ET NON PAS DES NÈGRES»: PIEL Y RAZA EN EL SIGLO XVIII*
}

\author{
Paola Martínez Pestana
}

Torrelodones (Madrid)

\section{RESUMEN}

En el siglo XVIII tuvo lugar un creciente interés en torno a la naturaleza de la piel negra y el origen de los pueblos clasificados a través de ella que iría acompañado de una diferenciación cada vez mayor de su naturaleza respecto a los europeos blancos, llegando a ser considerados una variedad humana degenerada, una especie distinta o, en ocasiones, animales inferiores. La piel y la raza fueron de la mano en la historia natural del hombre, la cual comprendía no sólo aspectos anatómicos y fisiológicos, sino también la historia de las naciones, la historia sagrada y la reflexión estética.

PALABRAS CLAVE: Piel. Negro. Raza. Historia de las naciones. Degeneración. Membrana reticular. Teoría humoral.

\section{«DES HOMMES NOIRS ET NON PAS DES NÈGRES»: SKIN AND RACE IN $\mathrm{XVIII}^{\mathrm{TH}}$ CENTURY}

\begin{abstract}
A growing interest in the nature of the black skin and in the origins of the peoples classified under this trait was accompanied in the eighteenth century by an increasing differentiation of their nature from whites, to the point that they were considered either a degenerated variety of humans, a separate species or inferior animals. Skin and race go together in the natural history of man, wich comprises not only anatomical and physiological aspects, but also the history of nations, the Sacred History and the aesthetic reflection.
\end{abstract}

KEY WORDS: Skin. «Negroe». Race. History of nations. Degeneration. Malpighian membrane. Humoral theory.

* Este ensayo forma parte de una investigación doctoral desarrollada en el seno de los proyectos «Epistemología histórica; estilos de razonamiento científico y modelos culturales en el mundo moderno: El dolor y la guerra» (HUM2007-63267) y «Ciencia, política e imperio» (PE h. 2009). 
«Des hommes noirs», y no «des vrais Nègres»; así identificó Petrus Camper a los Magos de Oriente representados por maestros como Rubens o van den Tempel: la piel era negra, «mais cette peau couvroit un corps de charpente européenne» ${ }^{1}$. El creador del ángulo facial, conocido en siglos posteriores más por su contribución a la anatomía comparada y la craneometría que por su dedicación a las artes, expresaba de este modo en su Dissertation sur les variétés naturelles qui caractérisent la physionomie des hommes des divers climats (1792, en publicación póstuma) la necesidad de elucidar la diferente complexión y aspecto físico de las naciones a través de la historia natural del hombre - defendiendo la influencia del clima y el medio - y de una fórmula métrica basada en dos líneas trazadas del oído a la nariz y de la frente a los incisivos. La piel, junto a los distintos grados del ángulo formado por estas líneas, indicarían el origen de un individuo, o al menos el individuo sería correctamente representado gracias a ambos factores - color y complexión craneal-, obteniendo de este modo el negro un aspecto simiesco nunca antes visto y que, no obstante, se generalizará en este siglo ${ }^{2}$.

1 «Pero esta piel cubría un cuerpo de complexión europea»; CAMPER, P. (1792), Dissertation sur les variétés naturelles qui caractérisent la physionomie des hommes des divers climats..., París, Francart, p. 6.

2 Es muy conocida la ilustración, dentro de la mencionada obra de Camper, de una serie de perfiles con diverso ángulo facial: la medida de una estatua griega clásica era de 100 grados, el europeo medía 80 grados, asiáticos y africanos compartían 70 grados, siendo éstas las poblaciones con el ángulo más semejante al del orangután y el mono, de 58 y 42 grados respectivamente. Camper encuentra sobre todo «une analogie marquée entre la tête du Nègre et celle du Singe»/«Una marcada analogía entre la cabeza del negro y la del mono»; CAMPER (1792), p. 12. Según MeIJer, M.C. (1998), Race and Aesthetics in the Anthropology of Petrus Camper (17221789), Amsterdam, Rodopi, la intención de Camper era naturalizar la fisionomía de los no europeos frente a una opinión bastante frecuente en la época sobre la artificialidad o intervención intencionada en la formación de sus rasgos, algo que los hacía más depravados y bárbaros a los ojos de los europeos. Meijer intenta suavizar los propósitos de este anatomista que defendía el origen común de todas las variedades de la especie humana contrastándolo con las posteriores teorías en torno al prognatismo, basadas en la obra de Camper, que supuestamente defendían una interpretación poligenista. En mi opinión, la dicotomía monogenismo/poligenismo apenas es determinante en la emergencia de las razas, ambas posturas tienen más puntos en común que de controversia y participan de igual modo en la conformación de este nuevo objeto. Ambas, por ejemplo, fueron capaces de admitir esa geometrización de los individuos para alcanzar una medida común, la complexión física de todo un pueblo que Camper halló curiosamente a partir de ocho cráneos africanos y asiáticos, junto a otros cráneos europeos — no dice el número—, que el anatomista poseía en su gabinete. 
La expresión de «vrais Nègres», «auténticos negros», aparece con frecuencia en la época para aludir a lo que ya empezaba a llamarse raza negra, una complexión física profundamente determinada - en la mayoría de los casos con capacidades morales igual de condicionadas - aplicable a toda una nación, que se contrapondría a la idea de la negritud como un simple y superficial color de piel, la de los «hommes noirs» cuyo color era adjetivo y no sustantivo como en los «Nègres». Para algunos autores - Henry Home o Charles White - esta última denominación, o su correlato inglés «Negroe», resultaba más correcta al considerar que tales individuos no debían ser tratados siquiera de hombres. Llegando o no a tal extremo, eran ya pocos quienes podían hablar de los africanos negros sin encontrar en ellos algo más que un color o que unos meros rasgos locales. Miradas como la de Rubens o como la de Hogarth, quien en su Analysis on Beauty afirmaría que negros y blancos eran iguales si se les quitaba la piel, resultaban caducas ${ }^{3}$.

Las condiciones que dieron lugar a esta determinación esencial del color de piel, que dejó de ser considerada como un fenómeno intrascendente para convertirse en la marca externa de una profunda separación racial, es lo que se analizará en las siguientes páginas. Tales condiciones pueden ser resumidas en dos nuevas perspectivas que influirían en esta incipiente visión de la piel: la historia del hombre y de las civilizaciones, de las que se ocupa el primer apartado, en las que la historia natural y las teorías de la generación se vinculan tanto a la historia social como a la sagrada; y las experiencias anatómicas aplicadas a las distintas naciones, que se analizarán en el segundo, centradas ante todo en la piel del negro para atribuirle una naturaleza ruda y esclava, así como una imagen grotesca u horrenda desde la percepción estética.

\section{LA PIEl COMO VESTIGio de la Historia}

En 1787 el conde de Volney describía la esfinge de Giza como un rostro de rasgos «típicamente negros» para expresar una idea bastante peculiar en la época: la gran cultura egipcia, tan influyente en las civilizaciones griega y europea, había sido fundada originariamente por una población de «vrais Nègres». Los egipcios habían perdido ya en el siglo de Volney el color de sus prósperos antepasados mezclándose con la sangre de griegos y romanos, pero

3 Hogarth, W. (1805), Analyse de la beauté, París, Levrault, Schoell, pp. 200-201. Sobre la posición crítica de Hogarth respecto a la supuesta opacidad de la piel negra y al desmedido interés que despertaban los casos de alteración del color, ver pp. 4 y 14. 
mantenían esa impronta común - esa constitución y rasgos de auténticos negros - tal y como la conservaba la impertérrita esfinge. Volney no entendía la raza como una constitución física y moral determinante en capacidades como la inteligencia, o el grado de civilidad y de progreso - prueba de ello era el desafío de atribuir la sofisticación egipcia a población negra-, pero sí compartía una impresión muy común forjada en este siglo: la legibilidad de la línea genealógica de un pueblo ancestral en el cuerpo de un individuo. «La physionomie est une sorte de monument propre en bien de cas à constater ou éclaircir les témoignages de l'Histoire, sur les origines des peuples» ${ }^{4}$.

El color no está presente en la esfinge, pero con ella Volney hace evidente la utilidad que comenzaba a tener la raza para interpretar la historia del hombre y de las naciones, en muchos casos para dirimir a su vez la vejez de los continentes y la evolución de la Tierra. Las hipótesis sobre la historia de las migraciones, por ejemplo, podían verse esclarecidas gracias a la comparación de las diferencias o semejanzas fisionómicas, y esto a su vez permitía dar cierta luz a la reflexión sobre la unidad o diversidad de la especie humana y sobre el desarrollo de sus diferencias.

Una de las hipótesis sobre las migraciones más influyentes en este sentido fue la del conde de Buffon, quien a través de ellas identificó el blanco como el color auténtico y original del hombre, y el clima como la principal causa de las diferencias entre las naciones tras su expansión por las diversas latitudes de la tierra ${ }^{5}$. Tal hipótesis había surgido de las semejanzas observadas entre determinados animales de América respecto a los de Asia o Europa. En el caso del hombre, la semejanza era también notable, por lo cual Buffon encontró razonable sospechar el origen común de la especie humana -igual que en aquellos grupos animales - y su posterior diversificación a través de las migraciones, de las cuales daba cuenta, sobre todo, el diverso color de piel acorde a cada clima: más oscuro cuanto más tórrido.

4 «La fisionomía es una especie de monumento adecuado en muchos casos para constatar o esclarecer los testimonios de la Historia sobre el origen de los pueblos»; VOLNEY, C.-F. de Chasseboeuf, conde de (1787), Voyage en Syrie et en Égypte, pendant les années 1783, 1784 et 1785, tomo I, París, Volland, Desenne, p. 75. Curiosamente, esta opinión sobre los rasgos raciales de la esfinge fue secundada posteriormente por el propio sociólogo panafricanista W.E.B. Du BoIs (1915) en su obra The Negro, Nueva York, Henry Holt and Company. También Flaubert encontró aquellas facciones «negroides» en la esfinge.

5 Buffon, G.-L. Leclerc, conde de (1749), Histoire naturelle, générale et particulière: avec la description du cabinet du roi (1749-1788), vol. III, París, Imprimerie Royale, p. 528. 


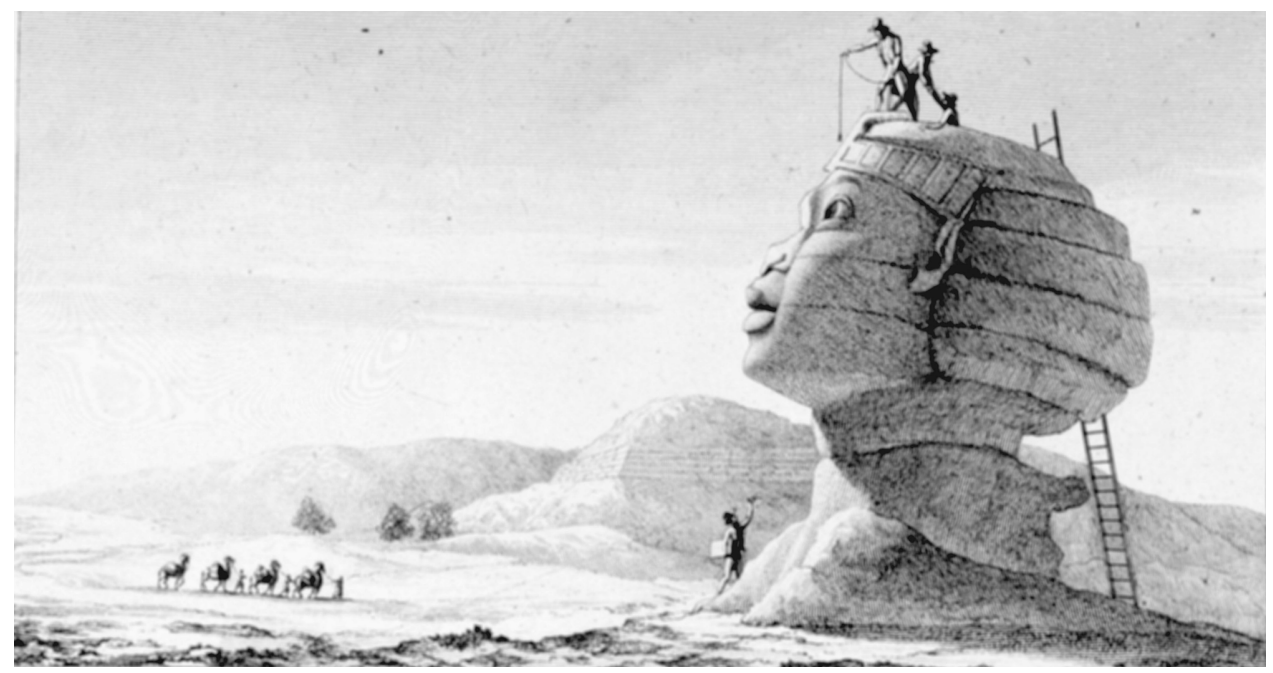

Miembros de la expedición de Egipto miden las pirámides. 1798-1801, este grabado forma parte de las láminas de Dominique Vivant Denon, Voyage dans la Basse et la Haute Égypte, París, 1802, colección privada, París, Francia.

Es significativo el hecho de que esta hipótesis se diera dentro de lo que Jacques Roger identifica como la primera auténtica historia natural tras la obra de Plinio ${ }^{6}$, es decir la única que, entre otros aspectos, no necesitará del apoyo de la historia sagrada en sus argumentaciones. No es en el Génesis en lo que piensa Buffon cuando habla de un hombre original blanco, y esto resulta relevante teniendo en cuenta el gran uso que se hizo de la interpretación bíblica respecto a la historia natural del hombre. Era muy recurrente aún en el siglo XVIII la tradición que atribuía el color negro de la piel a la maldición

6 Roger, J. (1989), Buffon. Un philosophe au jardin du roi, Évreux, Fayard, p. 247. De hecho, el que hubiera sido escrita como una auténtica historia natural hizo que fuera recibida con polémica y se tachara de libertina. Según el historiador francés fue así acusada por los jansenistas -en buena medida por haber sido alabada por los jesuitas, a quienes consideraban culpables del declive de la religión por su tolerancia hacia ciertas obras subversivas-. El conde de Buffon es tildado de nuevo pirroniano, por mostrar cierto escepticismo al sugerir las verdades físicas como sólo probables y por presentar los valores morales como convenciones. Además, se le acusaba de presentar al ser humano como un animal más, y se le reprendía por afirmar que la edad del mundo había sido eterna, contradiciendo así el Génesis. Sobre tales críticas ver en la misma obra de ROGER (1989), pp. 250-251. 
proferida por Dios sobre la descendencia de Cam, hijo de Noé. Siendo ésta la más conocida, surgieron además en la época otras interpretaciones apoyadas en las Escrituras que, como veremos, adquirieron gran importancia. Buffon se ciñe a lo estrictamente natural: el color blanco de piel es escogido como el original por ser el propio de climas temperados, y en concreto los correspondientes al norte de Europa, donde suponía que la influencia climática era más suave y por tanto neutra. En cualquier caso, no es ya una cuestión de autoridad sagrada, sino física e incluso estética, pues además de ser el europeo el clima más adecuado, era el que producía gentes más bellas: «c'est sous ce climat qu'on doit prendre l'idée de la vraie couleur de l'homme, c'est là où l'on doit prendre le modèle ou l'unité à laquelle il faut rapporter tous les autres nuances de couleur et de beauté» ${ }^{7}$.

A pesar del origen compartido en el pasado, existía una gran separación en el presente: el hombre europeo era el más parecido a aquel prototipo ancestral; el negro africano, en cambio, debía ser el más alejado y sobre quien recayera por tanto la posibilidad de «regenerarse», volver al color y complexión originales, una vez habitara de nuevo los climas templados y se mantuviera allí durante varias generaciones ${ }^{8}$. La hipótesis de la degeneración se servía de la literatura sobre casos de alteraciones de color en la piel, sobre los negros blancos, o sobre hijos nacidos con un color distinto al de sus padres, un tipo de literatura que en el XVIII va a ser cada vez más prolífica. En muchas ocasiones, sin embargo, las observaciones narradas no conducían siempre a las mismas conclusiones, no siendo aceptada por todos los autores la acción del clima en este tipo de cambios de la piel e imponiéndose como causa la transmisión generacional. Casi como en una comedia de enredo con un final feliz, en muchas de estas historias se descubría, tras una serie de dudas y conjeturas descartadas, que el sujeto en cuestión tenía un antepasado del mismo color que ahora compartía el descendiente, salvando de este modo el honor de la madre ${ }^{9}$. No es de extrañar la mirada cómica de William Hogarth sobre este

7 «Es en este clima donde debe tomarse la idea del verdadero color del hombre, aquí es donde se halla el modelo o unidad a la que deben remitir todos los demás matices de color y de belleza»; BUFFON (1749), p. 528.

8 Buffon (1749), vol. IV, p. 381-382.

9 La Royal Society recogió muchos de estos casos, como por ejemplo: BIRD, W. (1696), An account of a negro-boy that is dappel'd in several places of his body with white spots, Philosophical transactions of the Royal Society of London, 19; BATE, J. (1760), An account of the remarkable alteration of colour in a negro woman, Philosophical transactions of the Royal Society of London, 51, Part I.; PARSONS, J. (1766), An account of the white negro shown before the Royal Society, Philosophical transactions of the Royal Society of London, 55. La 
tipo de casos y sobre la recreación y curiosidad de aristócratas y médicos que los atestiguaban, expuesta en su grabado The Discovery, donde una mujer negra - que antes debía ser blanca, por el retrato que de la misma aparece y la leyenda: «qui color albus erat, nunc est contrarius albus»- es hallada y observada con sorpresa y casi alborozo en su propio lecho y con el pecho descubierto, a la manera satírica con la que el mismo pintor y Alexander Pope habían tratado el parto de los diecisiete conejos de Mary Toft.

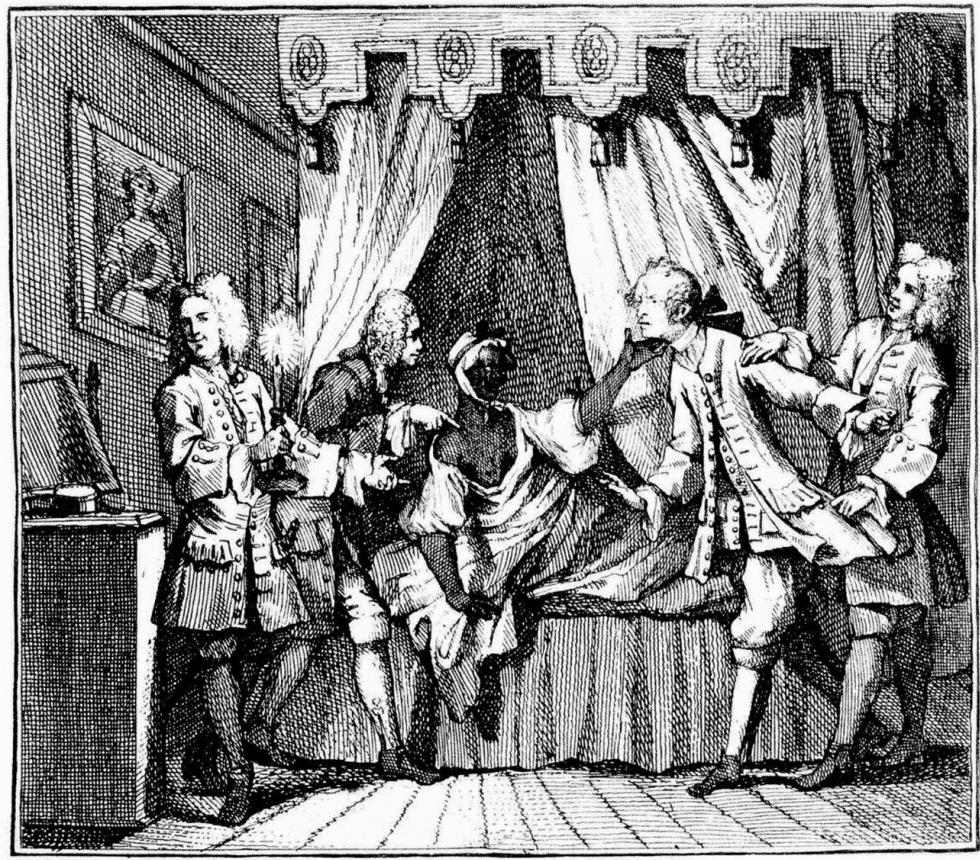

William Hogarth, The Discovery, c. 1743, grabado, Royal Library, Windsor Castle, Windsor, Reino Unido.

obra de P.-L.M. de MAUPERTUIS (1744), Dissertation physique à l'occasion du nègre blanc, Leyden, conocida sobre todo por la edición ampliada de 1745, Vénus physique, utiliza el fenómeno del negro blanco como prueba contra el preformacionismo. Para Maupertuis un sujeto tan distinto a sus progenitores y antepasados sólo podía explicarse como resultado de un proceso de generación epigenético. También existían casos de metamorfosis de blanco a negro, como el que describe G. IMLAY (1797), A topographical description of the Western territory of North America, Londres, J. Debrett. 
La idea de la degeneración y la posibilidad de la regeneración propuesta por Buffon, marcará la historia de las variedades humanas, siendo utilizada sobre todo por quienes defendieron la unidad de la especie. Para el médico y firmante de la Declaración de Independencia de los Estados Unidos- Benjamin Rush no sólo existía la posibilidad de la regeneración en los negros, sino que debían - era aconsejable para ellos - regenerarse, pues su color de piel era síntoma evidente de una enfermedad de características semejantes a la lepra. Una lepra benigna, empero, cuyas molestias no iban más allá de un pelo «lanoso», una cara abotargada, o insensibilidad en el tacto. Las dolencias eran de una índole más bien moral, su color les hacía infelices, pues aunque «they appear to be satisfied with their color, there are many proofs of their preferring that of the white people ${ }^{10}$. Con este cuadro médico Rush modificaba el concepto de degeneración de Buffon tras haber considerado que ciertos rasgos físicos del negro no podían ser explicados por el clima, como eran los labios «hinchados» o la nariz «aplastada». Además, la regeneración podía ser más rápida al no depender tanto del tiempo como de la ciencia que pudiera hallar una cura ${ }^{11}$. El hombre blanco tenía, por su parte, la obligación moral de ayudar al negro en esta empresa: «If the color of the negroes be the effect of a disease, instead of inviting us to tyrannise over them, it should entitle them to a double portion of our humanity, for disease all over the world has always been the signal for immediate and universal compassion» ${ }^{12}$.

Más cercano a la interpretación buffoniana, esto es, aceptando la influencia climática, Samuel Williams llegó a calcular el tiempo concreto que habría de pasar para que el negro deviniera blanco en un clima apropiado ${ }^{13}$. Si se mantenían cruzamientos continuos con blancos eran necesarias cinco generaciones que, siendo cada una de veinticinco años aproximadamente, equivalían a unos ciento veinticinco años para dar lugar a la regeneración completa. Me-

10 «Aunque aparentan estar satisfechos con su color, existen muchas pruebas de que prefieren el de los blancos»; RUSH, B. (1799), Observations intended to favour a supposition that the black color (as it is called) of the Negroes is derived from the leprosy, Transactions of the American philosophical Society, IV, p. 297.

11 Rush menciona diversas experiencias médicas que podían ir bien encaminadas para esta cura, como el uso del zumo de melocotón restregado sobre la piel; RUSH (1799), pp. 296-297.

12 «Si el color de los negros es el efecto de una enfermedad, en lugar de incitarnos a tiranizarlos, esto les daría derecho a una porción doble de nuestra humanidad, pues la enfermedad ha sido siempre y en todo lugar la señal para la compasión inmediata y universal»; RUSH (1799), p. 295.

13 WiLliams, S. (1794), The Natural and Civil History of Vermont, Walpole, N.H., Isaiah Thomas \& David Carlisle, pp. 391, 392. 
diante la sola acción del clima y sin cruzamiento alguno con blancos, el lapso debía ser de cuatro mil años. Para los indios se precisaba sólo de seiscientos años, sin necesidad de mestizaje, pues su tez era más clara y, por consiguiente, su estado de degeneración debía ser menor.

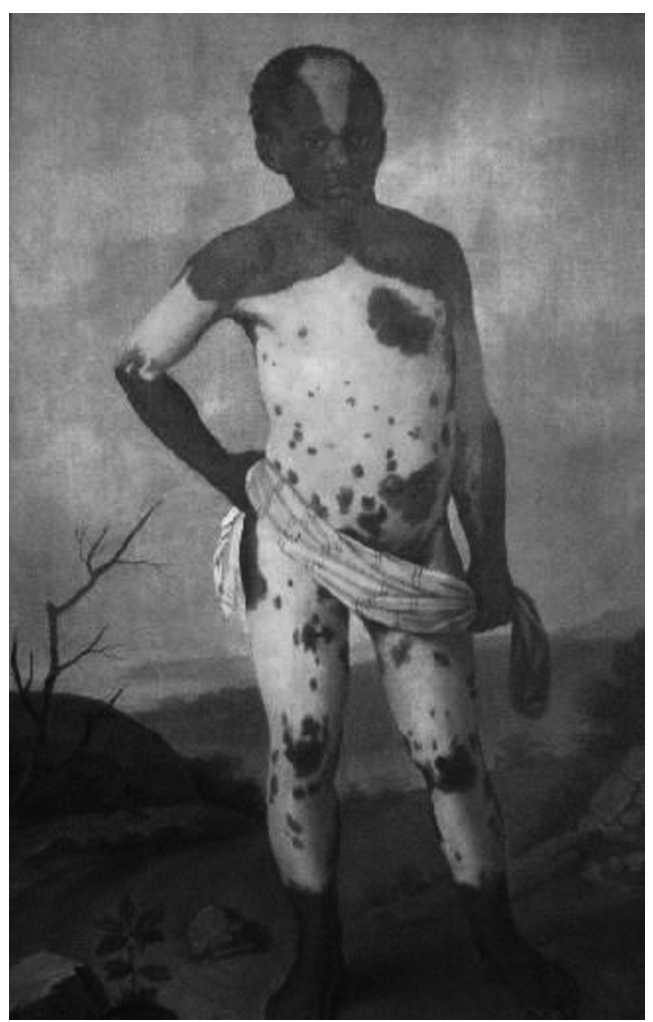

Joaquim M. da Rocha, Negro pío, 1786, óleo sobre lienzo, Museo Nacional de Antropología, Madrid, España.

El albinismo y ciertas despigmentaciones de la piel fueron a menudo consideradas como una vuelta al color original de la humanidad, que normalmente se suponía blanca.

Existía, no obstante, una dificultad objetada tiempo atrás por autores como Thomas Browne, el propio Robert Boyle o el barón de La Hontan sobre este tipo de hipótesis basadas en el clima, que radicaba en la observación de que 
en las mismas latitudes donde se encontraban pueblos de piel negra existían otras naciones a quienes el ardor del sol no afectaba del mismo modo, como ocurría en los climas tropicales del Nuevo Mundo, donde el color de la piel no llegaba a ser tan oscuro como en las mismas latitudes de África ${ }^{14}$. Buffon había sorteado este problema gracias a una conjetura propuesta en su Histoire naturelle, y era que el Nuevo Mundo había emergido de los océanos mucho más tarde que el viejo continente. De esta manera se podía explicar que pueblos como los peruanos o los mejicanos, al haber habitado estas nuevas regiones en tiempos posteriores a la población de África, no hubieran tenido tiempo de adquirir a través del sol el intenso color de los africanos. No habían tenido tiempo de degenerar del todo ${ }^{15}$. Benito Jerónimo Feijoo había discutido esta objeción - en concreto la del barón de La Hontan - de un modo quizá más audaz aún que Buffon, al no considerar imprescindible el cambio del color tras habitar nuevos climas: «Puede el Clima Etiópico producir la negrura, sin ser necesario para conservarla. Las causas segundas muy frecuentemente no son necesarias para la conservación de los efectos que producen. El oro se produce en las entrañas de la tierra, que viene a ser como patria suya; y extraído de ella se conserva siglos, y más siglos, sin que cosa alguna elemental altere su intrínseca textura. ¿Qué repugnancia hay en que la influencia del País Etiópico induzca tal textura en el semen prolífico de sus naturales, que después en ningún País extraño pueda alterarse, o por lo menos no pueda alterarse, sino en mayor espacio de tiempo, que el que hasta ahora se pudo observar?» ${ }^{16}$. Para el benedictino español no suponía ninguna enfermedad o abe-

14 En el siglo XVII el color de la piel negra ya suscitaba curiosidad entre anatomistas y filósofos de la Naturaleza. En 1646, Thomas Browne expuso sus observaciones al respecto en Of the blackness of Negroes; BRowne, Th. (1928), Pseudodoxia epidemica. En The works of sir Thomas Browne [1646], Londres, Faber and Gwyer. R. BoYLE (1664) esgrimirá razones similares a las de Browne en oposición a una explicación ambientalista del color de piel, dentro de sus Experiments and considerations touching colours, Londres, Henry Herringman. Según el médico portugués con el que el barón de La Hontan conversa en la relación de sus viajes, el color negro de los etíopes no se desvanecía en ellos ni tan siquiera cuando habitaban latitudes más frías durante generaciones. LA HonTAN, L.A., barón de (1703), Nouveaux voyages dans l'Amérique septentrionale, La Haya, les frères L'Honoré, citado por PoPKIN, R.H. (1987), Isaac La Peyrère (1596-1676): His Life, Work and Influence, Leiden, Nueva York, Colonia, Brill, pp. 115-132.

15 Buffon, G.-L. Leclerc, conde de (1778), Suplementos a la Histoire naturelle, tomo V, París, Imprimerie Royale, p. 266.

16 FeIJOO, B.J. (1778), Color etiópico, Teatro crítico universal, tomo VII, Madrid, Real Compañía de Impresores y Libreros, p. 87. La originalidad, erudición y rigor con que Feijoo resolvió problemas como las causas del color del pueblo etíope, el origen de la población 
rración el que los etíopes y sus descendientes se mantuvieran negros a lo largo de sus vidas y de las generaciones.

La de Buffon no fue la primera conjetura sobre la degeneración de la especie humana, aunque sí fue él mismo quien acuñó el término. Tampoco debía ir acompañada necesariamente de una explicación ambientalista, a pesar de ser lo más usual. A principios de siglo, el jesuita Joseph-François Lafitau había sugerido la idea de que los indios americanos de Canadá hubieran provenido originariamente de pueblos helenos y pelasgianos, subrayando así el origen común de americanos y europeos. La semejanza en las costumbres de estos indios con las de los primeros habitantes griegos, incitó al jesuita a sostener tal hipótesis ${ }^{17}$, pero las diferencias no podían ser explicadas por el clima, sino por la imaginación maternal. El color diverso de cada nación era explicado por su gusto primigenio en embadurnarse de colores negros - los africanos-, o rojos - los indios norteamericanos-. Estos colores impresionaban de tal manera la imaginación de las mujeres que los niños nacían finalmente con la tonalidad preferida. Como apoyo a esta teoría, Lafitau recurre al capítulo treinta del Génesis donde se explica la estrategia de Jacob para criar corderos con el color y manchas deseados, situándolos frente a vallas del mismo color y formas, para distinguirlos de los corderos de Labán ${ }^{18}$. También a la imaginación maternal atribuye Lafitau los demás rasgos característicos:

americana, los caracteres nacionales, la determinación climática en los rasgos físicos y morales de las naciones, o la influencia de la imaginación materna sobre los mismos, presentando hipótesis sobre la transformación de los continentes y de sus habitantes años antes de la gran Historia natural de Buffon o de tratados sobre el color de la piel como el de Le Cat, se aborda en Martínez Pestana, P., Feijoo y el debate internacional en torno a la raza y la historia de las naciones, Biblioteca virtual Saavedra Fajardo, Murcia, 2009. Estos problemas fueron tratados por Feijoo en los discursos Mapa intelectual y cotejo de naciones (1728), Solución del gran problema histórico sobre la población de la América, y revoluciones del orbe terráqueo (1733), Color etiópico (1736), del Teatro crítico universal, y la carta IV del tomo I de las Cartas eruditas y curiosas (1742), sobre el efecto de la imaginación materna en los hijos de color que nacían de padres blancos, que se recogen en la selección de textos realizada por la misma Biblioteca virtual Saavedra Fajardo en 2009.

17 Es conocida la irónica crítica de Voltaire a las teorías de Lafitau. El philosophe se burla de la comparación que realiza entre costumbres tan ambiguas como el sedentarismo, y de su tesis sobre la influencia de la imaginación maternal en el color, rasgos y complexión de cada nación. Si Lafitau esgrime la cita bíblica de los corderos de Josué, Voltaire se pregunta por qué no se volvieron verdes al tener siempre delante hierba que pastar. VOLTAIRE, F.M.A. (1827), Essai sur les moeurs et l'esprit des nations [1756], vol. I, París, Garnery, pp. 44-45.

18 LafitaU, J.-F. (1724), Moeurs des sauvages amériquains comparées aux moeurs des premiers temps, París, Saugrain l'aîné, C.E. Hochereau, p. 68. 
una nariz «aplastada», unos labios gruesos, siempre dependiendo de los gustos del lugar. El relativismo estético es asumido con naturalidad por Lafitau, a diferencia de otros autores como el propio Buffon.

A pesar de la aparente correspondencia entre los climas y las distintas variedades humanas, la explicación ambiental no era para muchos del todo satisfactoria. En la época aparecieron otras posibles maneras de relacionar el color de piel con el clima sin necesidad de atribuir a éste la causa última, sino haciendo intervenir a la providencia en la historia del hombre. Eran las hipótesis de Henry Home, o del propio Kant. El jurista Henry Home, lord Kames, en sus Sketches of the history of man (1774), criticó con vehemencia la explicación buffoniana del clima. El escocés esgrimía la antigua objeción sobre la conservación del color de los ancestros en los individuos trasladados a otras latitudes: «Those who ascribe all to the sun, ought to consider how little probable it is, that the colour it impresses on the parents should be communicated to their infant children, who never saw the sun ${ }^{19}{ }^{9}$. La desemejanza en el color, rasgos, complexión y actitud moral de las naciones era para Home de tal magnitud que debía ser atribuida a una naturaleza distinta e innata en cada una de ellas. No podía ser sino la providencia divina la que hubiera dotado desde los orígenes a cada especie humana de una complexión adecuada para su clima, y era por ello que, a su vez, cada clima proporcionaba los alimentos más adecuados a cada constitución ${ }^{20}$. El color de los negros, por ejemplo, era la mejor forma hallada por la providencia para que soportaran un clima tan feroz.

Paradójicamente, fue a través de la tesis de Buffon según la cual el Nuevo Mundo había emergido de los océanos tiempo después de la formación del viejo continente, que Home logró dar una explicación coherente con el Génesis sobre el origen separado de las especies humanas. Según Home, Dios había creado un segundo Adán en el nuevo continente, ascendiente de los nativos americanos, y esto lo había hecho en tiempos ulteriores a la época de Moisés, razón por la cual no era mencionado en la Biblia este nuevo linaje de hombres ${ }^{21}$. Además, para el resto de razas, Home adujo el episodio de la torre de Babel. Los primeros hombres habían alcanzado una diversidad lingüística y una incomprensión mutua tales que Dios decidió separarlos distribuyéndolos por distintos climas y dotando a cada pueblo de una constitución física

19 «Aquellos que todo lo atribuyen al sol deberían considerar cuán improbable es que el color que éste imprime sobre los padres sea transferido a los hijos, que nunca vieron el sol»; KAMES, H. Home, lord (1807), Sketches of the history of man, Edimburgo, Creech, p. 23.

20 KAMES (1807), pp. 18-19.

21 POPKIN (1987) enmarca la teoría de este segundo Adán en la tradición preadamita, p. 125. 
adecuada a su latitud asignada. Es por ello, dice Home, que a partir de ese momento cada raza — por su naturaleza o, esta vez sí, por el clima— derivó en una grado de civilización distinto. «Thus, had not men wildly attempted to build a tower whose top might reach to heaven, all men would not only have had the same language, but would have made the same progress towards maturity of knowledege and civilization $»^{22}$.

Una explicación teleológica muy semejante fue la planteada por Immanuel Kant, quien propuso una definición de las razas humanas a través de una interpretación bastante ecléctica. Asumiendo una concepción de la generación preformacionista y ovista, el filósofo asumió el origen común de la especie humana afirmando que ya en los ovarios de Eva se encontraban determinadas las futuras generaciones, definidas ya con una complexión diversa para adaptarse adecuadamente a los diversos climas a los que en un momento dado habrían de emigrar separándose. Junto a esta explicación teleológica, Kant presentaba asimismo el criterio de fertilidad de Buffon como prueba de la unidad de la especie, otro aspecto que lo diferenciaba de Home, quien lo había tachado de ineficaz señalando que el propio philosophe se había visto obligado a admitir como especies distintas determinados tipos de animales que podían reproducirse entre sí, como era el caso de ovejas y cabras, o camellos y dromedarios ${ }^{23}$. Kant no encuentra problema alguno en el principio de fertilidad para definir una especie, pero para las razas cabía preguntarse además cómo identificarlas acertadamente. Para el filósofo de Königsberg la respuesta estará en el color de piel, éste era el rasgo más evidente de la distinción racial, pues era el único que se transmitía invariablemente de generación en generación. Se trataba además de un rasgo superficial que indicaba una constitución interna distinta, una constitución que permitía sobrevivir a cada raza en las condiciones ambientales de su latitud correspondiente - la separación geográfica era necesaria por naturaleza-. Para Kant eran cuatro los colores de piel básicos correspondientes a las razas: blancos, cobrizos, negros y oliváceos, el resto eran colores mixtos derivados de ellos. El color influía además en características más profundas; así, en los negros, las propiedades de la dermis - que acumulaba excesivo flogisto por las altas temperaturas y las zonas pantanosas que a menudo habitaban-, hacían que olieran mal e

22 «Por tanto, si los hombres no hubieran tenido ese impulso frenético por construir una torre cuya cima alcanzara el cielo, no sólo habrían conservado el mismo lenguaje, sino que habrían desarrollado el mismo progreso hacia la madurez del conocimiento y la civilización»; KAMES (1807), p. 68

23 KAMES (1807), p. 10. 
influían en su carácter ${ }^{24}$.

Una interesante réplica a la defensa del origen común fue la del capitán Bernard Romans en $A$ concise natural history of East and West Florida (1775), donde critica la presunción de creer más fiel a la historia sagrada la hipótesis según la cual había un único tronco genealógico para el género humano y no varios. Para Romans, debía ser más acorde al designio divino una creación múltiple y separada de distintos tipos humanos que la creencia en una naturaleza sujeta a cambios accidentales - como defendió Buffon-, o a maldiciones divinas - como aquella interpretación de la condena de Cam25. Según la hipótesis de Romans, Dios había creado un Adán y una Eva de una especie distinta en cada parte del globo. Era ésta una idea atrevida, pero a su vez bastante interesada si consideramos la defensa del esclavismo por parte del autor, con cuya práctica intentó enriquecerse, y su notable desprecio hacia las supuestas cualidades de las razas no europeas. Respecto a los nativos norteamericanos, Romans los estima incapaces de desarrollar una civilización. Éstos intentan imitar las maneras europeas, pero a la mínima oportunidad «they will return like the dog to his vomit». "See there the boasted, the admirated state of nature», concluye Romans, con irónica referencia a las ideas rousseaunianas ${ }^{26}$. Los negros, por su parte, son descritos como traicioneros, ladrones, testarudos y holgazanes, no siendo estas cualidades tampoco accidentales o fruto de las circunstancias sociales y ambientales, sino más bien «natural to them, and not originated in their state of slavery» ${ }^{27}$. Romans responde así a la extendida opinión según la cual el negro poseía penosas cualidades debido a circunstancias sociales como la esclavitud. Para el propio Benjamin Rush, con su optimismo etnocéntrico, no sólo el color de los negros era una enfermedad reversible, sino que además sus «vicios», tales como «Idleness, Treachery, Theft, and the like, are the genuine off-spring of slavery, and serve as an argument that they were not intended by Providence for it» ${ }^{28}$.

24 Son tres los textos en los cuales Kant elabora su definición de raza humana: KANT, I., Des différentes races humaines [1775], Opuscules sur L'histoire, París, Flammarion, 1990; Determinación del concepto de raza [1780], En defensa de la Ilustración, Barcelona, Alba, 1999 y Sur l'emploi des principes téléologiques en philosophie [1788], Opuscules sur L’histoire, París, GF Flammarion, 1990.

25 POPKIN (1987), p. 127.

26 «Tornarán, como el perro hacia su vómito». «He aquí el arrogante, el admirado estado de naturaleza»; Romans, B. (1775), A Concise Natural History of East and West Florida, Nueva York, p. 38-39.

27 «Natural en ellos, y no originada por su estado de esclavitud»; ROMANS (1775), p. 105.

28 «Holgazanería, traición, robo, etc., son frutos genuínos de la esclavitud, y según esta 
Los negros podían por tanto para Rush devenir blancos y civilizados.

Otro ejemplo significativo del modo en que la historia sagrada intervenía aún en el XVIII en la explicación sobre el desarrollo de las razas humanas, es el del suizo Samuel Engel, para quien el color de los negros, «les Nègres véritables avec leur réticule, leurs cheveux crêpus ou lainés, leurs visage et nez écachés, ce que leur a fait donner de toute ancienneté le nom de Simes, leurs gosses lèvres, et enfin tout ce qui les caractérise, ne fauroit provenir d'aucune cause naturelle», sino de una causa sobrenatural: la maldición de Dios contra Caín, de quien los negros eran descendientes. Para explicar que éstos hubieran perdurado, Engel asume que el diluvio no pudo ser universal ${ }^{29}$. Tampoco acepta como explicación del color de los africanos la maldición que Dios pronunció sobre Cam, pues no todos sus descendientes habían sido negros, como babilonios, árabes o egipcios hacían patente ${ }^{30}$.

Cualquiera de estos casos, a pesar de las discrepancias, muestra cómo el sentido de linaje, que el término raza había detentado anteriormente - en su acepción de familia o estirpe-- no se perderá en su nuevo uso. La estirpe deviene raza, se amplía la extensión y se precisa la intensión. Hemos visto cómo la extensión llega al origen de los tiempos y se aplica a toda la humanidad, dividida o no en grandes grupos, veamos ahora cómo la intensión se especifica para dar un sentido a la raza aún más determinado, a través del análisis minucioso de la piel. Adoptemos ahora, para ello, la propuesta de Le Cat:

Laissons donc aux théologiens, aux historiens, aux antiquaires, etc., à discuter ces origines, qui se perdent dans le chaos de celle du monde; prénons le choses à l'état ou elles sont, de quelque source qu'elles viennent, et examinons en anatomiste, en physicien scrutateur des faits, les causes de la couleur de tous ces hommes blancs, basanés, noirs, cuivrés, etc. ${ }^{31}$

razón no están destinados por la Providencia a tales vicios»; RuSH, B. (1773), An adress to the inhabitants of the British settlements in America upon Slave-Keeping, Filadelfia, pp. 28-29.

29 «El auténtico negro con su retícula, sus cabellos crespos o lanosos, su rostro y nariz aplastados, lo que desde la antigüedad le dió el nombre de simus, sus lozanos labios, y en suma todo lo que le caracteriza, no provendría de una causa natural»; ENGEL, S. (1767), Quand et comment l'Amérique a-t-elle été peuplée d'hommes et d'animaux?, tomo IV, Amsterdam, Marc Michel Rey, p. 95.

30 ENGEL (1767), p. 76.

31 «Dejemos pues a los teólogos, a los historiadores, a los anticuarios, etc., discutir sobre estos orígenes que se pierden en el cahos del que surgió el mundo; tomemos las cosas en el estado en que están, provengan de donde provengan, y examinemos en tanto que anatomistas, en tanto que físicos escrutadores de hechos, las causas del color de todos los hombres blancos, morenos, negros, cobrizos, etc.»; LE CAT, C.-N. (1765), Traité de la couleur de la peau hu- 


\section{DESCRIPCIONES Y CAUSAS ANATÓMICAS}

El origen del color y naturaleza del africano negro desconcertaba al europeo. En 1739, la Académie de Bordeaux proponía como tema anual de su concurso «la cause physique de la couleur des nègres». La piel del negro, su color, necesitaban ser explicados. Pierre Barrère, ganador del premio, proponía una solución a la cuestión hallando un proceso fisiológico interno y ciertos rasgos anatómicos diferentes respecto de los blancos. Las pruebas que aportaba Barrère se basaban en observaciones sobre cadáveres de esclavos analizados por él mismo en Cayena, en la Guayana francesa. Así, había hallado, con una experiencia semejante a la de Alexis Littre ${ }^{32}$, esto es, tras macerar un trozo de epidermis en agua, cómo ésta mantenía cierta tonalidad oscura que normalmente se atribuía a la membrana reticular de Malpighi, pero que llegaba a ser semejante a la de otros cuerpos de europeos blancos. Por ello, Barrère no aceptó que la tonalidad de la membrana reticular fuera el factor decisivo del color de los negros, debía haber alguna otra sustancia en la piel que la oscureciera ${ }^{33}$.

Barrère sospechó que debía tratarse de una sustancia análoga a la bilis que él mismo había hallado en los cadáveres de esclavos. El anatomista había

maine en général, de celle des nègres en particulier et de la métamorphose d'une de ces couleurs en l'autre, soit de naissance, soit accidentellement, Amsterdam, p. 23.

32 Alexis Littre llevó a cabo la disección de la piel de un «maure» para comprobar si la suposición de Malpighi era cierta, a saber: que las dos capas, dermis y epidermis de la piel, al separarlas eran blancas, mientras que por otro lado la membrana mucosa aparecía negra, por lo que sería sobre ésta donde recaería la causa del color de los negros. Littre puso a macerar un trozo de epidermis en agua templada, considerada por los anatomistas como un poderoso disolvente, y otro trozo en alcohol, ambos durante siete días, pero de ellos no se desprendió tinte alguno. Asimismo metió otro trozo en agua hirviendo, que produjo sobre la superficie exterior de la epidermis ciertas ampollas con un licor claro en el interior que al enfriarse adquirió cierta textura gelatinosa; tampoco había el menor indicio de algún jugo oscuro que hubiera emergido con la ebullición. Littre concluyó, al no ver desprenderse tinte alguno, que esta membrana no contenía ninguna sustancia que diera color a la piel. El color debía atribuirse a la acción del sol sobre las capas más superficiales de la dermis. Tal experiencia de Littre aparece relatada en LitTRE, A. (1743), Diverses observations anatomiques. En Histoire de l'Académie Royale des Sciences. Année 1702, París, G. Martin, J.B. Coignard, Frères Guerin, pp. 30-32.

33 BARRÈRe, P. (1741), Dissertation sur la cause physique de la couleur des nègres, de la qualité de leur cheveux et de la dégénération de l'un et de l'autre, París, Pierre-Guillaume Simon, p. 3. 
observado que esta sustancia en los negros era muy oscura, de manera directamente proporcional a la intensidad de su color de piel, llegando a ser en los blancos de color amarillento. De igual modo, en los negros la sangre era de un rojo negruzco, y su intensidad también variaba en proporción al color de la piel, lo cual debía indicar una relación causal. A estas observaciones Barrère añadía otro curioso indicio a favor de su hipótesis: la exudación por parte de los negros de una grasa o sudor oscuro, de tal modo que si se les pasaba un paño sobre la piel, éste quedaba impregnado de un tinte negro ${ }^{34}$. Según Barrère, la bilis era segregada con mayor facilidad en la dermis gracias a las numerosas glándulas que a través de ella se disponían, por lo que quedaba más tintada que el resto del cuerpo. Los negros retenían este tinte con mayor facilidad por la peculiar pequeñez de sus poros.

Lo mismo explicaba el color de los cabellos de los negros, siendo las raíces de éstos uno de los lugares donde se segregaba la bilis negra. Además, la causa de la forma de este tipo de cabello, que Barrère define como la lana - observación muy común en la época, que animaliza sin duda al negro-, sería la forma espiral y la angostura de los propios folículos por donde salía cada pelo. La bilis y la forma de los folículos pilosos eran entonces la causa inmediata del color de la piel y de la naturaleza de los cabellos; pero además, la razón por la cual se mantenía este color a través de las generaciones era la transferencia seminal de los rasgos de familia. «Il est déjà avoué dans le monde savant que dans le germe des corps des animaux se trouvent comme concentrées toutes les parties qui les composent avec leur figure et leur couleur determinées; que ces parties se développent, s'étendent et s'épanouissent dès qu'elles sont mises en jeu et pénétrées par un fluide très fin et spiritueux, c'est à dire par la sémence du mâle» ${ }^{35}$.

Pierre Barrère abría con sus observaciones una puerta a la explicación humoral del negro, que seguirían autores tan destacados como Le Cat, Friedrich Meckel o Blumenbach, y que en gran medida convertiría el color en un rasgo temperamental, que afectaba a la actitud moral de la raza ${ }^{36}$. Para Clau-

\footnotetext{
34 BARRÈRE (1741), p. 5.

35 «Es ya un hecho reconocido en el mundo académico que en la semilla de los animales se encuentran como concentrados todas las partes que lo componen, con su figura y color determinados; que estas partes se desarrollan, se expanden y brotan en cuanto son puestas en juego y se las hace penetrar a través de un fluido muy fino y sutil, es decir, a través de la simiente del macho»; BARRÈRE (1741), p. 8.

36 WheEler, R. (2000), The complexion of race. Categories of difference in eighteenthcentury culture, University of Pennsylvania Press, indica el componente humoral y temperamental que mantenía en este siglo el término inglés para designar el color de piel, complexion.
} 
de-Nicolas Le Cat, la membrana mucosa de Malpighi se encontraba únicamente en los negros, y estaba formada por jugos de color oscuro segregados por las terminaciones nerviosas. No se trataba ya de bilis, pues ésta, a diferencia de lo que había observado Barrère, tenía el mismo color amarillento en todos los tipos humanos ${ }^{37}$. El color negro se debía, antes bien, a una sustancia compuesta de mercurio y azufre, a la cual llamó «æthiops», que ya había tenido ocasión de analizar en el ojo, en la membrana de la coroides ${ }^{38}$, así como en la tinta de una especie de calamar ${ }^{39}$. Le Cat había realizado una experiencia sobre esta tinta animal y el líquido contenido en los nervios humanos para mostrar que eran análogos al responder de manera similar: los mezcló con nitrato y con aguafuerte, fuertes disolventes que eliminaban el tinte de cualquier sustancia, y el resultado fue que ambos licores se habían mantenido incorruptibles en su color. A tal experiencia Le Cat añadía la consideración de que la tez de los negros se volvía aún más oscura cuando fallecían, de la misma manera que ocurría con aquellos calamares al morir ${ }^{40}$.

Le Cat secundaba las observaciones del anatomista Johann Friedrich Meckel, quien había diseccionado a un negro hallando que su glándula pineal era de un color más intenso y de una textura más consistente que la de los blancos, por lo que hizo recaer la causa del color de los negros en esta sustancia nerviosa, la cual daba su tinte característico a la piel a través de las terminaciones nerviosas y la membrana reticular formada por la segregación de és$\operatorname{tas}^{41}$. Por su parte, Le Cat había realizado también experiencias sobre el cerebro de un paciente negro de diecisiete años, hallando aquella tonalidad negra azulada que había mencionado Meckel. Afirmó haber repetido la misma observación por él mismo pero también «par plusieurs yeux anatomistes et non anatomistes $\rangle^{42}$, a los que presentaba el cerebro del negro y el cerebro del blanco sin desvelarles a quién pertenecía cada uno. Todos coincidían en que el cerebro de los negros tenía tonalidades más oscuras que el de los blancos ${ }^{43}$.

\footnotetext{
37 LE CAT (1765), p. 41.

38 LE CAT (1765), pp. 44-48.

39 LE CAT (1765), pp. 63-67.

40 LE CAT (1765), p. 69.

41 MeCKel, J.F. (1769), Recherches anatomiques. I. Sur la nature de l'épidermie et du réseau, qu'on apelle Malpighien. II. Sur la diversité de couleur dans la substance médullaire des Nègres. III. Sur la maladie du Nègre qui a fourni les observations des deux premiers articles, causée par un endurcissement stéatomateaux du péritoine, Mémoires de l'académie royale de Prusse, 1, art. 47, pp. 414-437.

42 «Por varios ojos anatomistas y no anatomistas»; LE CAT (1765), p. 56.

43 LE CAT (1765), pp. 53-56.
} 
Por otro lado, siendo la sustancia nerviosa del cerebro la causa fundamental del color de piel, así como del tipo de cabello, la transmisión generacional era explicada, como en Barrère, a través del semen, «car personne ne doute que le cerveau ne soit une partie spermatique, et comme l'amande féconde qui produit tout le reste de l'animal» ${ }^{44}$.

Claudia Benthien señala cómo esta nueva concepción convertía el color oscuro en una contaminación de la piel por parte de aquellas sustancias biliosas o nerviosas, consideradas, por su exceso o cualidad, como insanas. La piel era concebida como un órgano de excreción que debido a la peculiar anatomía dérmica del negro - muy gruesa y compacta, o con poros diminutos-, y a su sistema glandular - Barrère - o nervioso - Meckel, Le Cat-, quedaba tintada con peculiar intensidad ${ }^{45}$. Este tipo de experiencias y conclusiones llegaron a ser asumidas por los considerados padres de la clasificación racial, Johann Friedrich Blumenbach y el propio Kant ${ }^{46}$, quienes establecieron el número de razas basándose en sus colores básicos característicos — cinco para Blumenbach, cuatro para Kant-.

Pero no todo era consenso respecto a la interpretación humoral. El cartógrafo y botánico John Mitchell consideraba que «that strange phænomenon in Nature, the cause of the colour of negroes $\rangle^{47}$ era debido absoluta y únicamente a la acción del sol. Esto no era nuevo, ya vimos la explicación de Buffon, e incluso algunos de los que aceptaban la explicación humoral a su vez estimaron que ésta se debía en última instancia a la acción climática, como era el caso de Blumenbach. Lo insólito en Mitchell era que afirmaba no haber sido capaz de encontrar jamás la membrana reticular de Malpighi, y sospechaba

44 «Pues nadie duda de que el cerebro sea una parte espermática, como la almendra fecunda que produce todo el resto del animal»; LE CAT (1765), p. 58.

45 Benthien, C. (2002), Skin. On the cultural border between self and the world, New York, Columbia University Press, pp. 148-152.

46 Es Robert Bernasconi quien más ha defendido la importancia de Kant en la clasificación racial, quizá por haber pretendido dar una definición rigurosa al término raza. Existe, no obstante, cierto disenso a este respecto, pues para autores como John H. Zammito las hipótesis de Kant no tenían más que un carácter provisional, al ser expuestas como meras lecturas dentro de su universidad. Sobre tales interpretaciones, ver: BERNASCONI, R. (2001), Who invented the concept of race? Kant's role in the Enlightenment construction of race. En BERNASCONI, R. (ed.), Race, Malden, Blackwell, pp. 11-36; ZAMMITO, J.H., EIGEN, S. y LARRIMORE, M. (eds) (2006), The German invention of Race, Nueva York, State University of New York.

47 «Ese extraño fenómeno de la naturaleza, la causa del color de los negros»; MitcheLL, J. (1746), An Essay upon the Causes of the different Colours of People in different Climates. En Philosophical Transactions of the royal Society of London, vol. 43. Londres, C. Davis, p. 102. 
del estado cadavérico de la materia observada como medio poco seguro para conocer la piel tal como era en su estado natural. Mitchell estaba poniendo en duda a una de las máximas autoridades en el campo de la anatomía, Marcello Malpighi; más aún, se estaba mostrando suspicaz ante la experiencia de uno de los más diestros observadores al microscopio. Como apoyo a su observación, Mitchell hizo mención al cirujano y anatomista William Cowper, que tampoco había hallado la membrana, y quien había llegado a afirmar que en realidad nadie había logrado encontrarla jamás ${ }^{48}$. Por otro lado, Mitchell negaba la observación de Barrère según la cual al pasar un pañuelo sobre la piel de un negro quedaba impregnado de cierto aceite oscuro. Para Mitchell el sudor de los negros era tan transparente como el de los europeos ${ }^{49}$, afirmación que esgrimió como un argumento más contra las hipótesis en torno a la influencia de la bilis en el color de piel.

También Alexis Littre había aportado otra observación a favor de la acción del sol sobre el color de la piel, aunque no tan radical como la de Mitchell, pues no negaba la existencia de la membrana reticular y de cierta influencia de su color. Según Littre, el glande del hombre negro, en la zona cubierta por el prepucio, era completamente blanco, a diferencia de la zona que estaba al descubierto, lo cual tomó como prueba de que las partes humanas no expuestas al sol permanecían blancas, siendo la acción solar un agente fundamental en el color de piel. Curiosamente, el comentarista de tales experiencias en las Mémoires de l'Académie des sciences se permitió oponer a esta observación de Littre otra según la cual los recién nacidos de etíopes tenían en la punta del pene una pequeña mancha negra que, afirmaba, se extendería pasado el tiempo por todo el cuerpo. El autor sostenía que si bien tal propagación podía deberse a la acción del aire, del clima, su origen era en primer lugar innato ${ }^{50}$.

Las experiencias y explicaciones sobre el color de piel se vertebraban en torno a la controversia respecto a la influencia externa - medio, sol- o interna - fluidos - . Si bien las publicaciones sobre el tema se multiplicaron a lo largo - sobre todo en la segunda mitad - del XVIII, ya en el siglo anterior había aparecido en cierto grado la polémica. En 1618, el anatomista parisino Jean Riolan publicaba en su Anthropographia la experiencia por la que había separado un trozo de piel negra en dos tejidos, mediante la formación de una ampolla provocada artificialmente con ciertas sustancias químicas. Esto le había permitido observar el color y la textura de ambas capas, advirtiendo que

48 Mitchell (1746), p. 116.

49 Mitchell (1746), pp. 115-116.

50 LitTRE (1743), p. 32. 
la capa superior mantenía un color oscuro, mientra que la inferior resultaba ser blanca, de lo cual infirió que el color de este tipo de piel estaba producido por la luz solar, pues si el color se hallaba en la capa superior, que era la que estaba en contacto con el sol, y no en la interna, no debía haber ningún elemento subcutáneo que la oscureciera, sólo podía ser externo ${ }^{51}$.

La misma experiencia fue llevada a cabo por el anatomista del College of Physicians de Londres Alexander Read, quien en The Manual on the Anatomy or Dissection of the Body of Man (1642) describía cómo halló los mismos resultados llegando, sin embargo, a conclusiones radicalmente distintas. El color de la parte superior de la piel provenía de los humores internos del cuerpo, no del contacto con la luz solar. Estos humores, al ser exudados a través de la piel, tintaban la capa superior de la dermis con los restos que no lograban salir del todo al exterior ${ }^{52}$. El hecho de que la piel del hombre negro quedara mucho más tintada que la del blanco radicaba en una diferencia morfológica entre ambos tipos de piel: la negra tenía los poros más amplios que la blanca, por lo que transpiraba más, dando paso a una mayor cantidad de sudor y humores negros que dejaban sedimentos oscuros, lo cual dotaba a la piel de su color característico.

Esta experiencia, muy semejante a la de Barrère, coincidirá con observaciones muy recurrentes en el siglo XVIII, que mostrarán la piel del blanco como más abierta, traslúcida, no sólo respecto al color, sino en referencia a la propia transparencia de las emociones. El poeta Oliver Goldsmith en su History of the earth (1774) ensalzaba la piel blanca como la más bella, pues era «a transparent covering to the soul»" ${ }^{53}$, a través de la cual se revelaba toda la gama de las pasiones ${ }^{54}$. El recurso al principio de variedad como criterio de belleza para enaltecer la piel blanca fue bastante común en la época. Esta variedad hacía referencia a la diversidad y contraste tonales, a la emergencia del color, como ocurría con el rubor, o de una expresión en el rostro, que se solía atribuir únicamente a pieles blancas. William Hogarth, por el contrario, proporcionó soberbios contraejemplos frente a esta idea: en Marriage à la mode o en Captain lord George Graham in his cabin, la tez del negro se pre-

51 Klaus, S.N. (1998), A history of the Science of Pigmentation. En NordLund, J.J., Boissy, R.E., Hearing, V.J.; KInG, R.A. y Ortonne, J.-P. (eds), The Pigmentary System: Physiology and Pathophysiology, Nueva York, Oxford University Press, p. 6.

52 Klaus (1998), p. 7.

53 «Una envoltura transparente para el alma».

54 Goldsmith, O. (1824), A history of the earth, and animated nature, vol. I, Londres, William Charlton Wright, p. 268. 
senta igual o más vívida y llena de matices de expresión y color que en la del blanco $^{55}$.
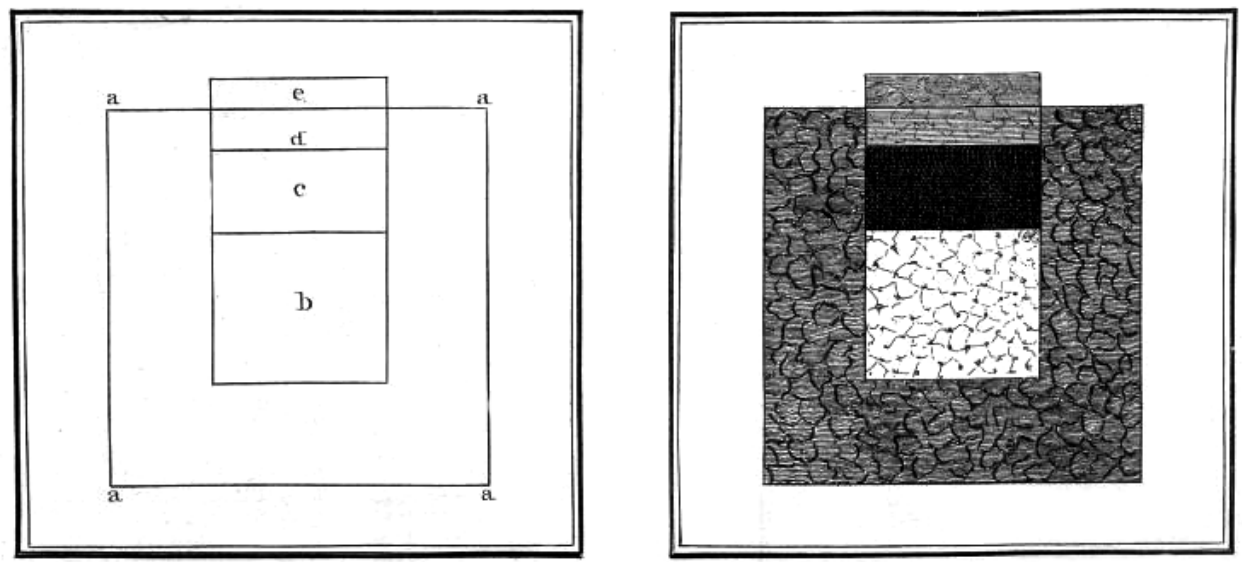

Charles White, Square portion of the skin of a negro, An account of the regular gradation in man, C. Dilly, 1799, lámina IV, wellcome Library, Londres.

La transparencia de la piel tenía en gran medida relación no sólo con el color, sino con el grosor de la piel negra. El cirujano y miembro de la Royal Society Charles White había señalado en su conocido ensayo An Account of the Regular Gradation in Man, and in Different Animals and Vegetables; and from the Former to the Latter (1799) el grosor de piel como indicio del distinto lugar ocupado en la gran cadena del ser, una concepción asumida dentro del creacionismo fijista, que consideraba igual de determinadas e inmutables la complexión e inteligencia de los seres en una escala jerárquica ${ }^{56}$. La piel en los negros era más gruesa que en los blancos, y en los monos lo era algo más que en los negros, estando estos más próximos a aquellos animales que a los blancos. El grosor de la piel negra, además, pese a servirles de protección frente al medio, hacía que tuvieran menos sensibilidad, lo cual les convertía

55 Dabydeen, D. (1985), Hogarth's blacks: images of blacks in eighteenth-century English art. Mundelstrup, Dangaroo Press, 1985.

56 GREEN, J.C. (1954), The American debate on the negro's place in nature, Journal of the History of Ideas, 15 (3), pp. 384-396, p. 390. 
en menos refinados y sensibles en general ${ }^{57}$.

El hecho de que la piel fuera más gruesa hacía asimismo que sudaran menos y olieran por ello peor, al acumularse los fluidos en la piel. Si el color era para Kant la evidencia de una raza, yendo en los negros acompañado del hedor de su piel contaminada, también para Henry Home el olor sería una de las diferencias fundamentales para distinguir a los africanos negros como raza aparte. Su fetidez no podía ser explicada por el clima, pues otros pueblos, como los abisinios, con clima semejante, no olían de tal modo. Tampoco podía ser explicado como falta de higiene; formaba parte de su naturaleza ${ }^{58}$. El juez jamaicano Edward Long había identificado de igual modo en su History of Jamaica (1774) el olor propio de los negros como confirmación de su diferenciación racial así como de su inferioridad. El clima no cambiaba esta naturaleza, tampoco cambiaba el hecho de que tuvieran piojos negros como los animales - los blancos sufrían de otro tipo de piojo blanco-, lo cual se debía a que el negro tenía más consanguinidad con el orangután que con el hombre blanco, que en realidad podía considerarse como el hombre, a secas ${ }^{59}$.

En numerosas ocasiones, la descripción del grosor de piel en los negros fue utilizada como justificación para el trabajo esclavo. Charles White ya había señalado su mayor resistencia y por tanto su aptitud para este tipo de trabajos; el hombre blanco, por el contrario, no tenía una constitución adecuada para trabajar la tierra de las colonias. Edward Tyson en A Philological Essay Concerning the Pygmies of the Ancients — publicado en 1699, pero cuya más famosa edición fue la de 1751 - también había sostenido que el clima había alterado las glándulas de los negros de manera que segregaban un humor diferente, dando lugar al color y cualidades de la piel negra, lo cual les había servido para soportar y trabajar mejor bajo el ardor de sus latitudes ${ }^{60}$.

Además de convertirlo en un ser afín a las bestias de carga, las nuevas descripciones de la piel hicieron del negro una figura horrible. No sólo los sentidos de los negros eran distintos — como el del tacto, por la densidad de su piel-, sino que, ante todo, ellos mismos eran extraños para los sentidos de los blancos. En 1766, en su Laocoonte, el poeta Lessing describía al hotentote como una figura ejemplar de lo que podía provocar disgusto estético. La misma idea se reflejaba en la Enquiry de Edmund Burke (1757), quien describía cómo un

57 SMith, M.M. (2006), How race is made, University of North Carolina Press, pp. 13-14.

58 KAMES (1807), p. 20.

59 CAntor, M. (1963), The image of the negro in colonial literature, The New England Quarterly, 36 (4), pp. 452-477, p. 465.

60 CANTOR (1963), p. 467. 
ciego de nacimiento al recobrar la vista había mostrado su horror al ver una mujer negra por vez primera. La experiencia del ciego de Molyneux era de este modo aplicada para asumir una conclusión bien diferente, que el disgusto ante el negro no era una respuesta adquirida, sino innata ${ }^{61}$. La observación de la piel blanca estaba hecha a la medida del hombre blanco, lo semejante era lo hermoso y natural, no sólo en la creación artística, sino en la naturaleza. Jonathan Swift ya lo había advertido en el viaje de Gulliver a Brobdingnag: «This made me reflect upon the fair Skins of our English Ladies, who appear so beautiful to us, only because they are of our own size, and their Defects not to be seen but through a magnifying Glass $\rangle^{62}$. Sólo un yahoo inglés consciente de ello podía realizar tal crítica a los juicios de valor esgrimidos por quienes decían basarse única y exclusivamente en matters of fact para presentar al inglés o al europeo como el hombre más bello, en lo físico y en lo moral.

Las observaciones de la piel negra dieron siempre resultados denigrantes para su morador, marcando su diferencia. Henri Grégoire ya había señalado esta jerarquización del color de piel como una «invention moderne», que había aparecido con «l'avarice coloniale». El color blanco se había convertido en un signo externo de distinción para la sociedad europea y colonial — como los bastones, los turbantes o los tatuajes en otros pueblos- a través del cual se pretendía marcar el rango. «On les a vus invoquer la Bible, en dénaturer le sens pour faire descendre du ciel l'esclavage, puis la contredire en niant l'unité de type dans la nature humaine, en soutenant que le noir est une race

61 Gilman, S.L. (1975), The figure of the black in german aesthetic theory, EighteenthCentury Studies, 8 (4), pp. 373-391; Chaouli, M. (2006), Lacoön and the Hottentots. En EIGEN, S. y LARRIMORE, M. (eds.), The german invention of race, Nueva York, State University of New York.

62 «Esto me hizo meditar sobre la diáfana piel de nuestras damas inglesas, que nos parecen tan bellas sólo porque son de nuestro tamaño, y sus defectos no pueden ser vistos sino a través de una lente de aumento». La desmitificación que Swift hizo de la piel blanca y su delicadeza en sus Viajes de Gulliver es interpretada en su contexto colonial de manera muy sugerente por HAwES, C. (1991), Three times round the globe: Gulliver and colonial discourse, Cultural Critique, (18), pp. 187-214, p. 200. Laura Brown llama la atención sobre la cronología de los poemas misóginos de Swift, que coinciden con su época más crítica respecto a las políticas coloniales de Gran Bretaña. La mujer engalanada sería la imagen del capitalismo y el imperialismo en Swift. BROwN, L. (1990), Reading Race and Gender: Jonathan Swift, EighteenthCentury Studies, 23 (4), pp. 425-443. Para comprender la crítica de Swift al proyecto de la Royal Society y su impostura al pretender basarse únicamente en matters of fact y emitir no obstante contínuos juicios de valor respecto al no europeo, ver MALCOLMSON, C. (2006), Gulliver's travels and studies of skin color in the Royal Society. En PALMERI, F., (ed.), Humans and other animals in eighteenth-century british culture, Aldershot, Ashgate. 
différente» ${ }^{63}$. Desde cualquiera de las posiciones mantenidas dentro de las controversias en torno a la piel negra - sobre su origen ambiental o interno, su naturaleza fija o susceptible a cambio, indicio de una especie separada o común-, la filosofía natural había situado a los «vrais Nègres», como bien afirma el abbé Grégoire, «au bas de l'échelle des êtres» ${ }^{64}$.

Recibido: 24 de febrero de 2009.

Aceptado: 3 de noviembre de 2009.

63 «Se les ha visto invocar la Biblia, distorsionando su sentido para hacer bajar de los cielos el esclavismo, después contradecirla para negar la unidad en la naturaleza humana, sosteniendo que el negro es una raza diferente»; GREGOIRE, H. (1826), De la noblesse de la peau ou Du préjugé des blancs contre la couleur des Africains et celle de leurs descendans, noirs et sang-mêlés, París, Baudouin frères, pp. 7-8.

64 «En lo más bajo de la escala de los seres». 
